\title{
Age Changes in the Lumbar Spinal and Intervertebral Canals
}

\author{
L. Twomey, BAppSc, BSc(Hons), PhD, ${ }^{1}$ J. Taylor, $\mathrm{MB}, \mathrm{ChB}, \mathrm{PhD}^{2}$ \\ ${ }^{1}$ School of Physiotherapy, Curtin University of Technology, Selby Street, Shenton \\ Park, Western Australia, 6008, '2Department of Anatomy and Human Biology, \\ University of Western Australia, Stirling Highway, Crawley, Western Australia, \\ 6009.
}

\section{Summary}

$A$ variety of measurements of the lumbar spinal canal $(S C)$ and intervertebral foramina $(I V F)$ are presented and compared in two adult age groups (48 individuals aged 20-35 and 48 individuals over 60 years) in both males and females. The dimensions measured in fresh post-mortem material include: mid-sagittal $(A P)$ and transverse diameters $(T D)$ of the $S C$; height, length and greater antero-posterior $(A P)$ width of the IVF and ligamentum flavum (LF) thickness at the lumbo-sacral level.

The data show a significant decline in the SC APD in both sexes, but the SC TD increases with ageing in males while it declines with ageing in females. The IVF height decreases with ageing but its AP width increases and its length increases. The LF shows a 50\% increase in thickness with ageing. These ageing changes in a 'normal' population provide the neurovascular bundle in the IVF with less 'room for manoeuvre' and support the view that minor additional pathology is more likely to lead to entrapment syndromes in the elderly than in the young.

Key words: Spinal canal; Intervertebral foramina; Lumbar spine; Spinal stenosis; Age changes.

The spinal canal (SC) and the intervertebral foramina (IVF) of the lumbar spine serve as containers and pathways for the terminal $2 \mathrm{~cm}$ of the spinal cord, the cauda equina and the nerve roots of the lumbar spinal nerves (Schmorl and Junghanns, 1971). With advancing age, these spaces may be reduced by soft tissue or osseous hypertrophy. Stenosis of the SC and IVF may compromise the neural structures or their vascular supply (Verbiest, 1975, 1976; Porter et al., 1980; Winston et al., 1984).

Growth of the sagittal and transverse diameters of the SC is virtually complete by 10 years of age (Knuttson, 1961), and remodelling and change in shape are said to be complete soon after this (Reichmann and Lewin, 1971). Stenosis is described as early as the second decade, but its prevalence increases with ageing. The hypertrophic bone changes usually associated with ageing may be super- 


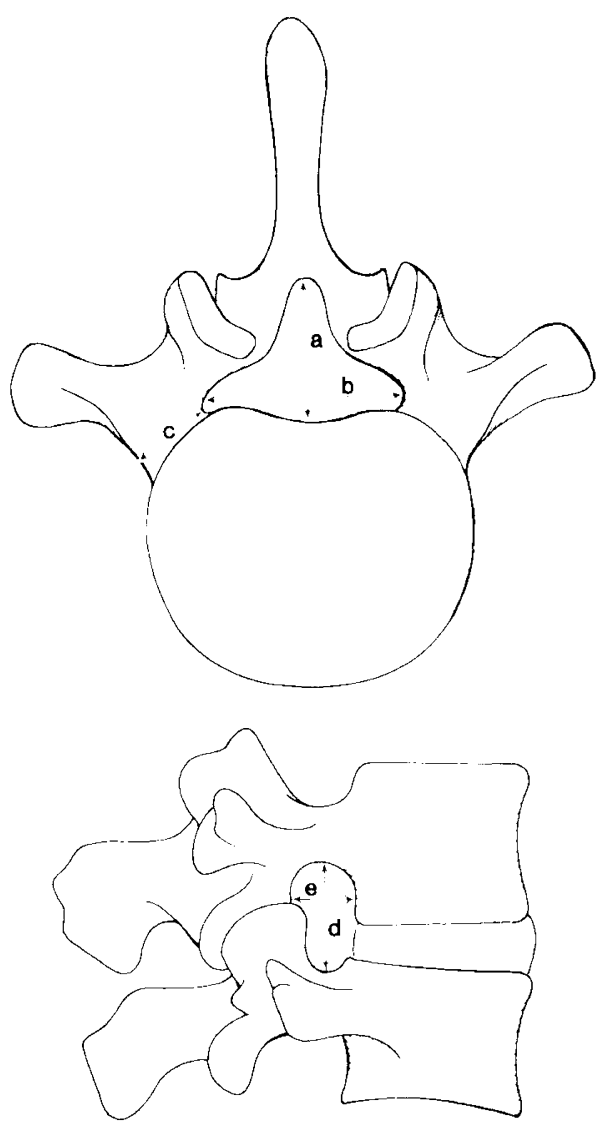

Figure 1 Diagrams demonstrating the measurements made of the lumbar spinal canal (above) and intervertebral foramina (below). $\mathrm{a}=$ mid-sagittal antero-posterior dimensions of spinal canal, $\mathrm{b}=$ lateral dimension of the spinal canal, $\mathrm{c}=$ length of the intervertebral canal, $\mathrm{d}=$ height of the intervertebral foramen, $\mathrm{e}=$ antero-posterior horizontal dimension of the intervertebral foramina.

imposed on a congenitally narrow canal (and it may be difficult to distinguish congenital from acquired stenosis). The lumbar SC is generally triangular in shape (Fig. 1) and may be trefoil at lower lumbar levels (Eisenstein, 1977). In lateral spinal stenosis this trefoil shape may be greatly exaggerated (Haworth and Keillor, 1962).

The IVF are the nerve root canals or tunnels (Dommisse, 1975). They are auricular in shape when viewed in lateral radiographs (Fig. 1), and the spinal nerves and their vessels descend obliquely through the 'wider' upper part of each canal (Schmorl and Junghanns, 1971; Sunderland, 1974). The length of each canal corresponds to the transverse width of the pedicles which form its roof and floor (Fig. 1). Although there are some doubts as to the proportion of the intervertebral (IV) canal occupied by the nerve roots and their accompanying vessels (Hadley, 1936; Cave, 1955; Sunderland, 1974), most authorities believe that there is usually adequate space to contain them (Sunderland 1974; Dommisse, 1975). The IV canal space can be compromised by disc narrowing and/or 
bulging with associated osteophytes at the vertebral body margins, by hypertrophy of the ligamentum flavum (LF), and by osteophytes laid down on the antero-medial aspect of the zygopophyseal (Z) joints (Farfan, 1973; Yong-Hing et al., 1976; Taylor and Twomey, 1986).

This study records age changes in the dimensions of the lumbar spinal canals and intervertebral canals in a 'normal' unselected population and discusses some possible biological mechanism for these changes and some clinical implications of the changes.

\section{Materials and methods}

The current study formed part of a more comprehensive study (Twomey, 1981), in which the whole lumbar spine, extending from T12 to S2 was removed routinely from each of 204 cadavers of Australian/European ethnic origin, which ranged in age from 1 day to 97 years. The complete series was grouped into six age groups to study age changes in structure and function (Taylor and Twomey, 1980; Twomey and Taylor, 1982, 1983, 1985), but the current study compares the dimensions of the SC, IVF and LF in only two age groups: young adults (20-35 years) and elderly subjects ( $60+$ years). There were 48 cadavers ( 24 male and 24 female) in each of the two age groups. The old and young groups of both sexes were of comparable average heights and weights.

All measurements were made directly in fresh, unfixed, hemisected spines, from which all muscles and the spinal cord, nerves and meninges had been carefully removed.

Dial vernier calipers (accurate to $0.05 \mathrm{~mm}$ ) were used to measure the median sagittal antero-posterior and the transverse dimensions of the SC (Fig. 1). This latter dimension was made from X-rays of the specimens taken with a long tubefilm distance and with the specimen in direct contact with the cassette. The antero-posterior diameter was measured directly on the specimens at the level of the lower margin of the vertebral body.

The height, length and greatest antero-posterior dimension of the bony lumbar IVF (Fig. 1) were directly measured at each level from L1-2 to L5-S1. The height and antero-posterior 'width' were measured within the canal using the calipers introduced from the external aspect of each IV canal. For length measurements, a specially constructed tool with a calibrated bolt was passed through the IV canal from the medial side. The bars of the tool were tightened against the lateral and medial margins of the pedicles bounding each IV canal, and the length was read off on the lateral side (Twomey, 1981).

Ligamentum flavum thickness was measured only at the L5-S1 level in the hemisected columns, using the calipers, to measure its thickest part, immediately postero-medial to the $\mathrm{Z}$ joint line.

\section{Results}

\section{Dimensions}

Vertebral canal. (a) Mid-sagittal antero-posterior diameter This is greatest (16$17 \mathrm{~mm}$ ) at upper and lower levels and least at mid-lumbar levels (Fig. 2). There 

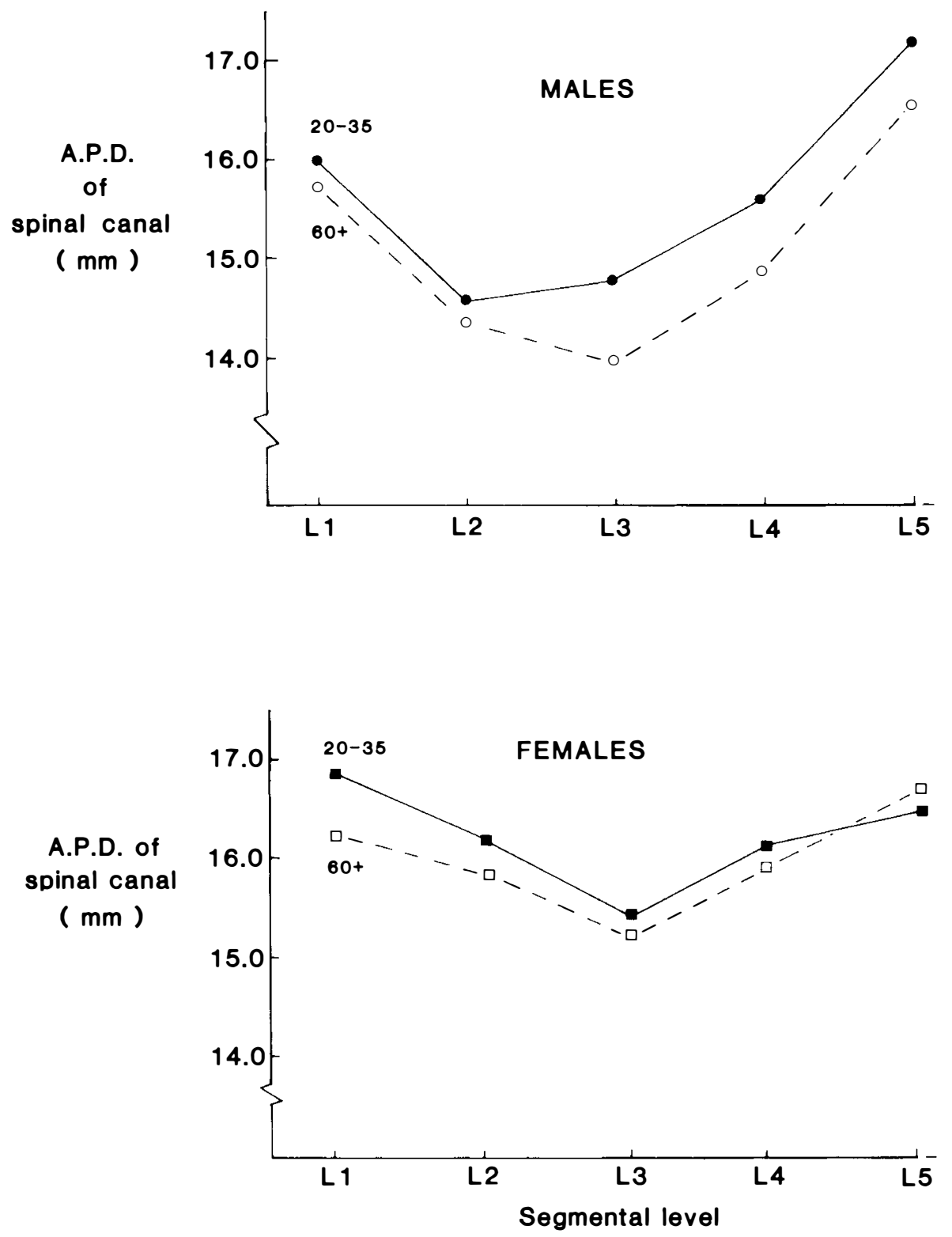

Figure 2 The antero-posterior diameter (APD) of the spinal canal in males and females.

is a consistent small decline with ageing (at 9 of 10 levels) which averages a $5 \%$ decline for the lowest three levels in males. The decline is statistically significant in males (p 0.01) but not in females (Table I).

(b) Transverse (interpedicular) width The data demonstrate a decline with ageing in females and an increase with ageing in males. The changes are most evident at L1 and L5 levels, where they are of the order of 5 to $6^{\circ}{ }_{0}$. They are statistically significant ( $\mathrm{p}$ 0.05) for both sexes (Table II). 
Table I The mid-sagittal antero-posterior dimensions of the vertebral canals in males and females between young adult life and old age

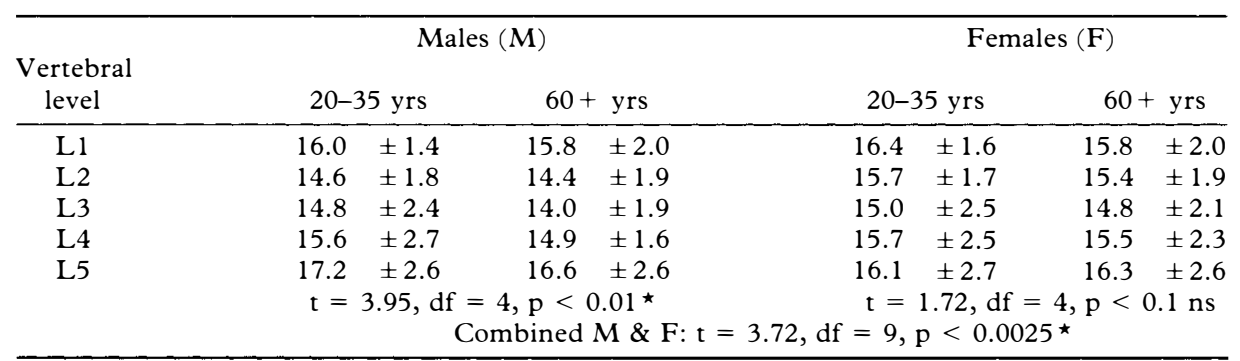

« significant.

ns not significant.

Table II The lateral dimensions $(\mathrm{mm})$ of the vertebral canals in males and females between young adult life and old age

\begin{tabular}{|c|c|c|c|c|c|c|c|c|}
\hline \multirow{3}{*}{$\begin{array}{c}\text { Vertebral } \\
\text { level }\end{array}$} & \multicolumn{4}{|c|}{ Males $(\mathbf{M})$} & \multicolumn{4}{|c|}{ Females $(\mathrm{F})$} \\
\hline & \multirow{2}{*}{\multicolumn{2}{|c|}{$20-35$ yrs }} & \multirow{2}{*}{\multicolumn{2}{|c|}{$60+y r s$}} & \multirow{2}{*}{\multicolumn{2}{|c|}{$20-35$ yrs }} & \multirow{2}{*}{\multicolumn{2}{|c|}{$60+y r s$}} \\
\hline & & & & & & & & \\
\hline L1 & 24.5 & \pm 3.3 & 25.9 & \pm 2.4 & 24.4 & \pm 2.6 & 23.3 & \pm 2.4 \\
\hline L2 & 24.5 & \pm 2.6 & 24.2 & \pm 2.3 & 23.9 & \pm 2.5 & 23.7 & \pm 2.4 \\
\hline L3 & 24.8 & \pm 2.2 & 25.9 & \pm 2.2 & 24.5 & \pm 1.9 & 24.1 & \pm 2.1 \\
\hline L4 & 26.3 & \pm 2.6 & 26.8 & \pm 2.2 & 25.1 & \pm 1.9 & 25.1 & \pm 2.0 \\
\hline \multirow[t]{2}{*}{ L5 } & 28.4 & \pm 3.1 & 30.2 & \pm 2.8 & 28.3 & \pm 2.2 & 26.7 & \pm 2.1 \\
\hline & \multicolumn{4}{|c|}{$\mathrm{t}=-2.45, \mathrm{df}=4, \mathrm{p}<0.05^{\star}$} & \multicolumn{4}{|c|}{$\mathrm{t}=2.20, \mathrm{df}=4, \mathrm{p}<0.05^{\star}$} \\
\hline
\end{tabular}

^ significant.

ns not significant.

Table III The maximum height of the intervertebral foramine (IVF) in males and females between young adult life and old age

\begin{tabular}{|c|c|c|c|c|c|c|}
\hline \multirow{3}{*}{$\frac{\begin{array}{l}\text { IVF } \\
\text { level }\end{array}}{\text { L1-2 }}$} & \multicolumn{2}{|c|}{ Males (M) } & \multicolumn{4}{|c|}{ Females $(\mathrm{F})$} \\
\hline & $20-35$ yrs & $60+y r s$ & \multicolumn{2}{|c|}{$20-35$ yrs } & \multicolumn{2}{|c|}{$60+y r s$} \\
\hline & \pm 2.1 & $15.0 \pm 1.9$ & 14.2 & \pm 1.8 & $\overline{14.1}$ & \pm 2.3 \\
\hline $\mathrm{L} 2-3$ & \pm 1.9 & \pm 2.6 & 15.7 & \pm 1.5 & 15.1 & \pm 2.7 \\
\hline L3-4 & \pm 2.2 & \pm 2.9 & 16.9 & \pm 1.4 & 15.5 & \pm 3.1 \\
\hline L4-5 & $15.6 \pm 2.2$ & \pm 3.4 & 15.9 & \pm 2.5 & 15.8 & \pm 2.5 \\
\hline L5-S1 & $13.2 \pm 2.6$ & $12.4 \pm 2.1$ & 13.4 & \pm 2.0 & 11.6 & \pm 2.1 \\
\hline
\end{tabular}

« significant.

ns not significant.

Intervertebral foramina. (a) Height The IVF height is greatest at mid-lumbar levels, particularly at L3-4, and least at the lower ends of the lumbar column, particularly at L5-S1 (Fig. 3). It declines with ageing at 9 of 10 age/sex levels and this decline is significant for females ( $\mathrm{p}$ 0.05) but not for males (Table III). The greatest decline is seen at lumbo-sacral levels $\left(13^{\circ}{ }_{0}\right.$ in females).

(b) Antero-posterior diameter $(A P)$ This is normally greater at the L5-S1 level than at higher levels (Table IV); it increases with ageing at all levels in males and at 3 of the 5 levels in females. At upper and middle levels in males it increases by $7-12^{\circ}{ }_{0}$. The increases are statistically significant in males (p 0.005) but not in females. 

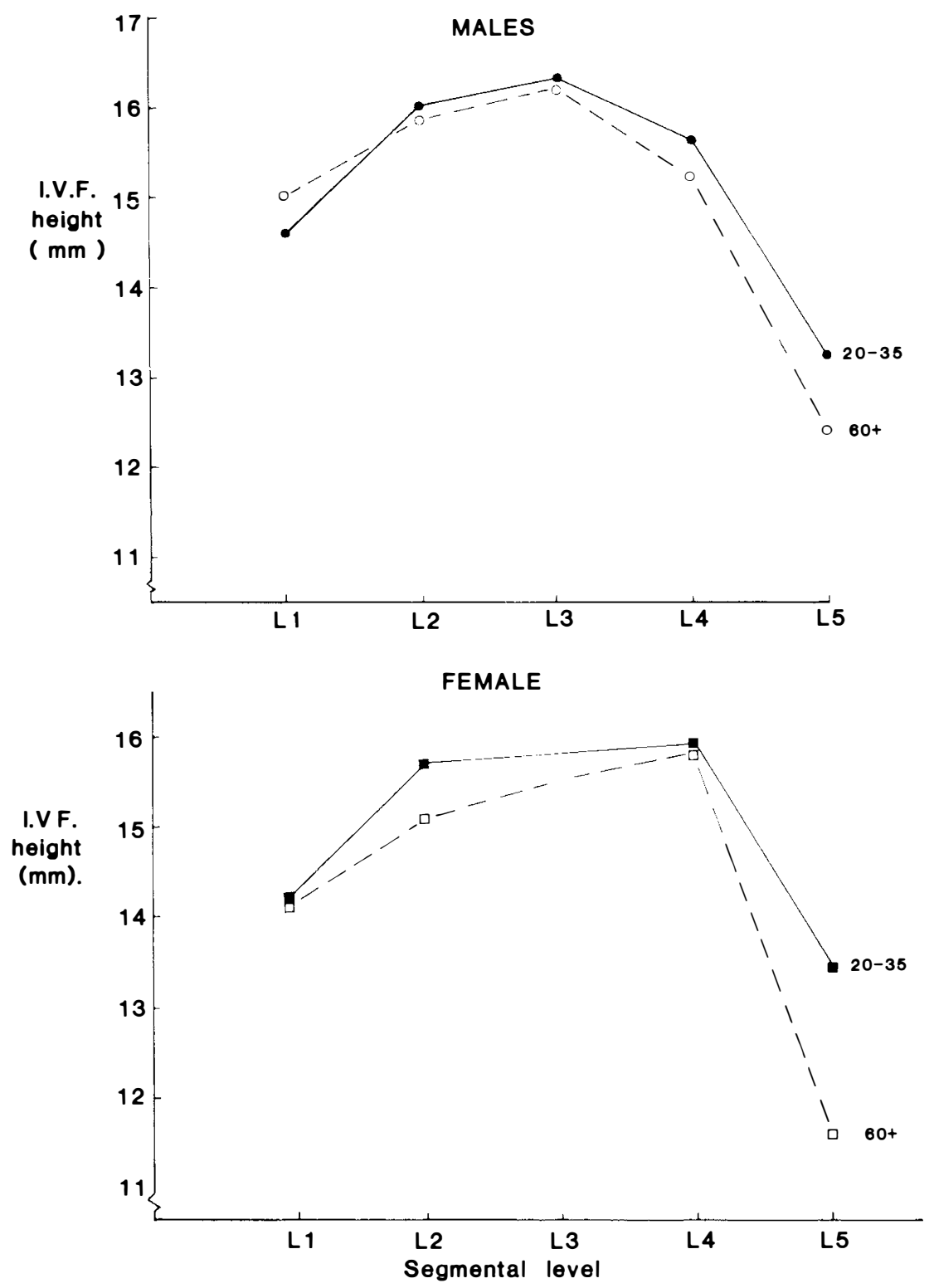

Figure 3 The height of the lumbar intervertebral foramina (IVF) in males and females.

(c) Length This normally shows a progressive increase from L1-2 to L5-S1; it also increases quite markedly with ageing, except at upper levels in males (Table $\mathrm{V})$. The largest increases are at the lower three levels in females and at L4-5 in males, which together average a $21^{\circ}{ }_{\circ}$ increase in length. Overall the increases are highly significant in females (p 0.005) but not in males.

Ligamentum flavum. The average thickness increases from $1.5 \mathrm{~mm}$ or $1.6 \mathrm{~mm}$ in males and females respectively to $2.2 \mathrm{~mm}$ and $2.5 \mathrm{~mm}$ respectively (Twomey, 1981). This represents a $47^{\circ}{ }_{0}$ increase in males and a $56^{\circ}{ }_{0}$ increase in females. 
Table VI Spinal canal indices:

(A) $\frac{\text { mid-sagittal diameter of the spinal canal (SC) }}{\text { antero-posterior diameter of the spinal canal (SC) }}$

\begin{tabular}{ccccc}
\hline $\begin{array}{c}\text { Vertebral } \\
\text { level }\end{array}$ & \multicolumn{2}{c}{ Males $(\mathrm{M})$} & \multicolumn{2}{c}{ Females $(\mathrm{F})$} \\
L1 & $20-35 \mathrm{yrs}$ & $60+\mathrm{yrs}$ & $20-35 \mathrm{yrs}$ & $60+\mathrm{yrs}$ \\
L2 & 0.51 & 0.50 & 0.60 & 0.54 \\
L3 & 0.46 & 0.44 & 0.55 & 0.50 \\
L4 & 0.45 & 0.41 & 0.50 & 0.47 \\
L5 & 0.48 & 0.44 & 0.53 & 0.48 \\
\hline
\end{tabular}

(B) $\frac{\text { transverse diameter SC }}{\text { transverse diameter } \mathrm{VB}}$

\begin{tabular}{|c|c|c|c|c|}
\hline \multirow{2}{*}{$\begin{array}{c}\text { Vertebral } \\
\text { level }\end{array}$} & \multicolumn{2}{|c|}{ Males $(\mathbf{M})$} & \multicolumn{2}{|c|}{ Females $(\mathbf{F})$} \\
\hline & $20-35$ yrs & $60+y r s$ & $20-35$ yrs & $60+y r s$ \\
\hline $\mathrm{L} 1$ & 0.58 & 0.62 & 0.68 & 0.60 \\
\hline L2 & 0.57 & 0.58 & 0.65 & 0.59 \\
\hline L3 & 0.56 & 0.58 & 0.63 & 0.56 \\
\hline L4 & 0.55 & 0.58 & 0.60 & 0.54 \\
\hline L5 & 0.54 & 0.59 & 0.61 & 0.54 \\
\hline
\end{tabular}

Table VII Intervertebral foramine (IVF) index:

Length of each intervertebral canal

Transverse diameter of the vertebral body $(\mathrm{VB})$ immediately caphelad

\begin{tabular}{lcccc}
\hline $\begin{array}{l}\text { Vertebral } \\
\text { level }\end{array}$ & Males $(\mathbf{M})$ & \multicolumn{2}{c}{ Females $(\mathrm{F})$} \\
\hline L1-2 & $20-35$ yrs & $60+$ yrs & $20-35$ yrs & $60+$ yrs \\
L2-3 & 0.45 & 0.44 & 0.45 & 0.44 \\
L3-4 & 0.47 & 0.45 & 0.47 & 0.46 \\
L4-5 & 0.47 & 0.46 & 0.51 & 0.48 \\
L5-S1 & 0.46 & 0.44 & 0.49 & 0.50 \\
\hline
\end{tabular}

hypertrophy' of bony vertebral elements in old age, previously reported in the same material (Twomey and Taylor, 1983; Taylor and Twomey, 1986). In particular there is:

(i) a horizontal spreading of the vertebral body, demonstrated as an increase in its antero-posterior and transverse dimensions (Twomey and Taylor, 1983), and

(ii) an increase in some of the bony dimensions of the posterior arches, e.g. the spinous processes increase their mid-sagittal vertical dimension (Twomey, 1981), while the lumbar $Z$ joints show evidence of bony sclerosis with hypertrophy and osteophyte development through middle and old age (Taylor and Twomey, 1986). 
This study shows a small reduction in the average antero-posterior diameter of the SC with ageing of about $5^{\circ}$ o for males. This natural age change compares with a 4 to $9^{\circ}{ }_{0}$ difference in the same measures between control and 'operated' groups reported by Winston et al., (1984), and with Porter's (1978) 7 to $14^{\circ}{ }_{0}^{\circ}$ difference in oblique sagittal measures between his control group and his group with symptomatic disc lesions. As the cross-sectional shape of the SC changes from triangular in young adult life to trefoil in the elderly (Verbiest, 1975), the small median sagittal reduction we have recorded with ageing would be associated with a larger reduction in the antero-posterior dimensions of the lateral recess. In retrospect, it may have been better to have measured the anteroposterior diameter from the upper end of the lamina rather than the lower end of the body as the former shows a greater reduction with ageing. Thus, it may be that either Porter's (1978) oblique measurement, or a para-sagittal antero-posterior measurement would provide better evidence of the hypertrophy of the walls of the SC than the standard mid-sagittal antero-posterior measurement. In this context, our previous studies using the same material (Twomey, 1981; Taylor and Twomey, 1986), demonstrated changes to the $Z$ joints and LF which form the postero-lateral walls of the SC, which would account for the change from a triangular to a trefoil shape.

There is a $50^{\circ}{ }_{0}$ increase in average LF thickness at the lumbo-sacral level. This, together with hypertrophy of the subchondral bone plate of the superior articular process of the $Z$ joints, and osteophyte formation into the LF (Taylor and Twomey, 1986), would reduce the para-sagittal antero-posterior dimensions of the lateral part of the SC. The hypertrophy of the anterior part of the subchondral bone of the superior articular process of the $\mathrm{Z}$ joint is probably a response to loading at the extremes of the normal sagittal range (Twomey and Taylor, 1985; Taylor and Twomey, 1986).

(b) The interesting observation that the interpedicular distance increases in males and declines in females with ageing (Tables II and VI) suggests that different influences predominate in males than in females. In males, the increase in transverse diameter of the vertebral body with ageing appears to 'carry' the pedicles out laterally. In female adults, the increase in transverse diameter of the vertebral body is less than in males (Twomey, 1981). However, osteoporosis is much more prevalent in elderly females than in elderly males (Lane and Vivorita, 1984; Pogrund, 1985), and the lesser increase of the transverse diameter of the vertebral body in females involved a transverse spreading of the lumbar vertebral bodies, associated with significant loss of the transverse trabeculae of vertebral cancellous bone (Twomey and Taylor, 1982; Preteux et al., 1985). Since the internal trabecular structure of the vertebral body is in direct continuity with that of the pedicles, a similar mechanism of 'transverse expansion' of the pedicles may accompany the changes previously described in the vertebral bodies. This increase in pedicle width could account for both the reduction in interpedicular distance and the increase in IV canal length in elderly women.

The increasing trefoil shape of the SC noted particularly in older males (Verbiest, 1975) would relate in part to the increased interpedicular distance observed in our study, and in part to the bony hypertropy of the superior articular process (SAP) and lamina at the two $\mathrm{Z}$ joints and to the thickening of the LF where they cover these joints. 


\section{Intervertebral foramina}

The changes noted in this study are a reduction in the height and increases in the antero-posterior diameter and length of the lumbar IVF and canals (Tables III and V). The reduced height, significant only in females (Table III), relates to the reduced length of the column noted in a previous study (Twomey, 1981). This loss in length (or stature) has been shown to be due to osteoporosis (Twomey and Taylor, 1983). The loss in IVF height could also be related to changes in the posture of the lumbo-sacral spine with ageing (Twomey, 1981). Despite a flattening of the lumbar lordosis from L1 to L4, which would tend to increase the IVF height, the loss in vertebral body height is still sufficient to be the predominant feature in the overall reduction of IVF height. At the lumbosacral junction, on the other hand, both the postural change (an increase in lordosis) and the height loss combine to produce a significant decline in the vertical dimensions of the IVF).

The increased length of the IV canal (Table IV), particularly at lower levels, relates to the increased transverse diameter of the vertebrae (Table VII), to hypertrophy of the $Z$ joints which form its posterior boundary, and in females to significant 'thickening' of the pedicles (Table V). These changes contribute both to the increased IV canal length and to the increasing trefoil shape of the SC.

The increased length of the IV canal and decreased IVF height both provide the neurovascular bundle with 'less room for manoeuvre' within the IV canal. This could compromise the neural structures in older people.

The observations of Larsen (1983) showing the scalloping of the posterior surfaces of lumbar vertebrae, which is most marked laterally, particularly with ageing, would explain our surprising observation of significant increase in the antero-posterior diameter of the upper part of the IVF in old age (Table III). This probably represents the 'erosive' effect of the spinal nerve roots on the posterior surface of the vertebral body. It suggests that although disc bulging and $\mathrm{Z}$ joint hypertrophy may narrow the lower part of the lateral IV canal, the nerve usually retains adequate space in the upper canal by virtue of this scalloping. Our static measurement probably measures the maximum available space and takes no account of the 'dynamic' form of lateral spinal stenosis associated with mobile segment instability. Moreover, the significant reduction in the vertical dimensions of the IVF, together with the increase in IV canal length, give the neurovascular bundle less overall space, and may force the bundle further down and into the narrow interior part of the IV canal. This argument highlights the potential importance of a change in lumbar posture, such as flattening of the lumbar lordosis, in relieving pressure and providing relief, by widening the vertical dimensions of a compromised IV canal.

Stenosis of the SC and IV canals, due to LF and bony hypertrophy, and to changes in posture and stature, is greatest at the lower levels in the lumbar spine (White and Panjabi, 1978). While some authorities (Ramsay, 1966; Schmorl and Junghanns, 1971) have attributed the principal factor to LF thickening and have described the LF as thickening to $9 \mathrm{~mm}$ at lumbo-sacral levels, it is generally considered that apparent LF thickening may be due in large part to the underlying hypertrophic bone changes, since anterior 
osteophytes from the $\mathrm{Z}$ joints at the LF attachments to the lamina 'grew into' the LF (Yong-Hing et al., 1976; Twomey, 1981).

\section{Clinical implications}

It is important that clinicians who see a highly selected population should be aware of 'normal' age changes found in an unselected population. Porter et al., (1980) showed that subjects with narrowed spinal canals are up to 11 times more likely than those with a normal canal to suffer from nerve root entrapment when affected by additional pathology, such as intervertebral disc prolapse. The narrowing of the lateral gutters of the SC and of the adjacent IV canals was also considered by Verbiest (1975) to contribute to stenosis and neurogenic claudication.

Heliovaara et al., (1986) showed a correlation between a narrowed $\mathrm{Z}$ joint interarticular distance within the SC and sciatica, and concluded that those individuals with considerable bony hypertrophy causing a marked reduction in SC space, were at greater risk from stenotic pressure after disorders such as lumbar disc bulging or protrusion. The work of Verbiest (1975, 1976), Porter et al., (1980), Winston et al., (1984) and Heliovaara (1986) support the view that minor structural changes, such as those described in the SC and IV canals in this study in an 'unselected' ageing population, make the subjects more vulnerable to entrapment syndromes and nerve root claudication syndromes in the event of any added acute pathology.

\section{References}

CAve AJE 1955 Osteo-arthritis deformans of the Luscka joints. The Lancet 176-179.

DoMISSE GF 1975 Morphological aspects of the lumbar spine and lumbo-sacral region. Orthopaedic Clinics of North America 6:163-175.

EISENSTEIN S 1977 The morphometry and pathological anatomy of the lumbar spine in South Africa negroes and caucasoids with specific reference to spinal stenosis. Fournal of Bone and foint Surgery 59-B:173-180.

FARFAN HF 1973 Mechanical Disorders of the Low Back. Lea and Ferbiger, London.

HADLY LA 1936 Apophyseal subluxation - disturbances in and about the IV foramen causing back pain. Fournal of Bone and foint Surgery 18:428-433.

HAWORTH JB, KEILLOR GW 1962 Use of transparencies in evaluating the width of the spinal canal in infants, children and adults. Radiology 79:109-114.

Heliovaara M, Vanharanta H, Korpi J, Troup JDG 1986 Herniated lumbar disc syndromes and vertebral canals. Spine 11(5):433-435.

KNUTSSON F 1961 Growth and differentiation of the post-natal vertebrae. Acta Radiologica $55: 401-408$.

LANE JM, Vigorita VJ 1984 Osteoporosis. Orthopaedic Clinics of North America 15(4):711-728.

LARSEN JL 1983 The posterior surface of the lumbar vertebral bodies. Spine 10(1):50-58.

Pogrund HA, Bloom RA, MenCzel J 1986 Preventing osteoporosis: current practices and problems. Geriatrics 41(5):55-71.

PORTER RW, HibBert CS, WICKs M 1978 The spinal canal in symptomatic lumbar disc lesions. fournal of Bone and foint Surgery 60-B(4):485-487.

Porter RW, Hibbert CS, Wellman P 1980 Backache and the lumbar spinal canal. Spine 5(2):98105.

Preteux F, Bergot C, Laval-Jeantet AM 1985 Automatic quantification of vertebral cancellous bone remodelling during ageing. Anatomic Clinica 7(3):203-208.

RAMSAY RH 1966 The anatomy of the ligamenta flava. Clinical Orthopaedics and Related Research 44:129-140.

Reichmann S, Lewin T 1971 Growth processes in the lumbar neural arch. Zeitschrift fur Anatomie und Entwicklungsschichte 133:89-101. 
Schmorl G, Junghanns H 1971 The Human Spine in Health and Disease. 2nd ed. New York and London, Grune and Stratton.

SUNDERLAND S 1974 Meningeal-neural relations in the intervertebral foramen. fournal of Neurosurgery 40:756-763.

TAYLOR JR, TWOMEY LT 1980 Sagittal and horizontal plane movement of the human lumbar vertebral column in cadavers and in the living. Rheumatology and Rehabilitation 19:223-232.

TAYLOR JR, TWOMEY LT 1986 Age changes in lumbar zygapophyseal joints: observations on structure and function. Spine 11(7): 739-745.

Twomey LT 1981 Age Changes in the Human Lumbar Spine. PhD Thesis, University of Western Australia.

TWOMEY LT, TAYLOR JR 1982 Flexion creep deformation and hysteresis in the lumbar vertebral column. Spine 7(2):116-122.

TwOMEY LT, TAYLOR JR 1983 Sagittal movements of the human lumbar vertebral column: a quantitative study of the role of the posterior vertebral elements. Archives of Physical Medicine and Rehabilitation 64:322-325.

Twomey LT, TAYLor JR 1985 Age changes in lumbar intervertebral discs. Acta Orthopaedica Scandinavica 56:496-499.

VERBIEST H 1975 Pathomorphological aspects of developmental lumbar stenosis. Orthopaedic Clinics of North America 6(1):177-195.

VERBIEST H 1976 Fallacies of the present definition, nomenclature and classification of the stenoses of the lumbar vertebral canal. Spine 1:217-225.

White AA, Panjabi MM 1978 The Clinical Biomechanics of the Spine. JB Lippincott Company, Philadelphia.

Winston K, Rumbaugh C, Colucci V 1984 The vertebral canals in lumbar disc disease. Spine 9(4):414-417.

YoNG-Hing MD, REILly J, KIRKALDY-WILlis WH 1976 The ligamentum flavum. Spine 1(4): $226-234$. 